\title{
КЛИНИЧЕСКИЙ СЛУЧАЙ ЛЕЧЕНИЯ ОБШИРНОЙ КЕРАТОКИСТЫ ТЕЛА И ВЕТВИ НИЖНЕЙ ЧЕЛЮСТИ С ОДНОМОМЕНТНОЙ РЕКОНСТРУКЦИЕЙ ДЕФЕКТА КОСТНЫМ АЛЛОТРАНСПЛАНТАТОМ ГОЛОВКИ БЕДРЕННОЙ КОСТИ В СОЧЕТАНИИ С НЕТКАНЫМ \\ ТИТАНОВЫМ МАТЕРИАЛОМ СО СКВОЗНОЙ ПОРИСТОСТЬЮ
}

\section{A CLINICAL CASE OF TREATMENT OF EXTENSIVE KERATOCYSTS OF THE BODY AND BRANCHES OF THE LOWER JAW WITH SIMULTANEOUS RECONSTRUCTION OF THE DEFECT WITH A BONE ALLOGRAFT OF THE FEMORAL HEAD IN COMBINATION WITH A NON WOVEN TITANIUM MATERIAL WITH THROUGH POROSITY}

D. Dedikov

Summary. This study presents a clinical observation on the treatment of extensive keratocysts occupying $1 / 3$ of the entire volume of the lower jaw using the method of reconstruction of bone wounds using a bone allograft of the femoral head. Keratocyst - (primary cyst), formed from odontogenic epithelium in those places where there are teeth. Keratocysts grow, as a rule, along the body of the jaw and lead to its pronounced deformation. In most cases, this is an accidental finding when performing an $x$-ray examination of the jaws, or patients seek help from a doctor with complaints of already pronounced and long-existing deformity of the jaw.

Keywords: lower jaw, posttraumatic deformity, spongy bone, femoral head, bone Bank, allogeneic bone.

\author{
Дедиков Дмитрий Николаевич \\ ФГБОУ ВО «Самарский государственный медицинский \\ университет» Министерства здравоохранения $Р \Phi$, \\ Самара; главный врач, врач челюстной-личевой хирург \\ высшей категории, Научно-Практический Центр \\ челюстно-лицевой хирургии и стоматологии, «АВЕРС» \\ Краснодар \\ avers_23@mail.ru
}

Аннотация. В данном исследовании представлено клиническое наблюдение по лечению обширной кератокисты занимающей $1 / 3$ от всего объема нижней челюсти с применением методики реконструкции костных ран при помощи костного аллотрансплантата головки бедренной кости. Кератокиста (первичная киста), образуются из одонтогенного эпителия в тех местах, где имеются зубы. Кератокисты растут, как правило, вдоль тела челюсти и приводят к ее выраженной деформации. В большинстве случаев, это случайная находка при выполнении рентгенологического обследования челюстей, либо пациенты обращаются за помощью к врачу с жалобами уже на выраженную и продолжительно существующую деформацию челюсти.

Ключевые слова: нижняя челюсть, посттравматическая деформация, губчатая кость, головка бедренной кости, костный банк, аллогенная кость.

\section{Введение}

$\mathbf{P}$ еконструкция дефектов лицевого скелета с использованием аутогенной кости неизменно остаётся стандартом в реконструктивной челюстно-лицевой хирургии и хирургической стоматологии [2, $3,5$,$] . Применение аллогенных материалов, аллотранс-$ плантатов кости требует выполнения определённой

технологии получения, консервации, методов скрининга доноров и методов стерилизации. Пересадка аутокости представляет самый естественный и эффективный способ лечения дефектов и деформаций костей лицевого скелета и по праву считается золотым стандартом, поскольку свойства трансплантатов остаются сохранными. Но не всегда представляется возможным получить должное количество аутокости для рекон- 


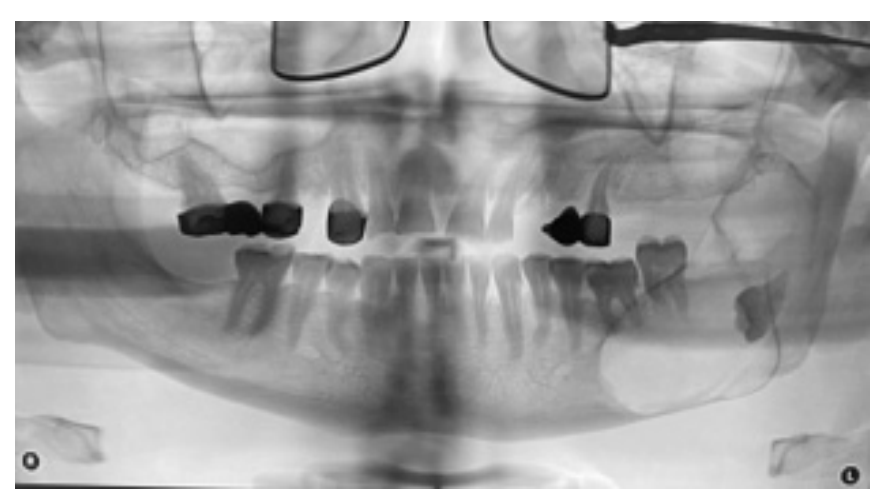

Рис. 1. Обширное, объемное новообразование. Тотальное поражение тела, ветви и отростков нижней челюсти слева

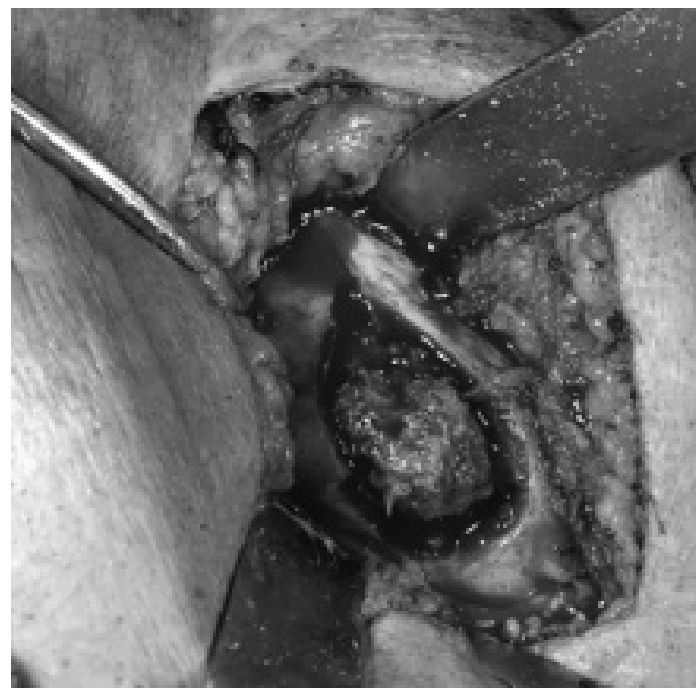

Рис. 3. Тело нижней челюсти деформированно процессом, наружная и внутренняя кортикальная пластинка истончена. Участок кисты

струкции образовавшегося дефекта без нанесения дополнительной травмы организму человека и возникает вопрос об использовании материала сходного по своим биологическим свойствам к тканям, утраченным по разным причинам [4]. Аллогенная трансплантация кости - занимает существенную часть в лечении обширных дефектов кости, прежде всего, при операциях протезирования и реконструкции после удаления опухолей кости. Наряду с аллогенными трансплантатами кости, используют аутологичную костную ткань, материалы из бычьей кости и искусственные материалы, а также живые культуры клеток хряща и кости (тканевая инженерия).

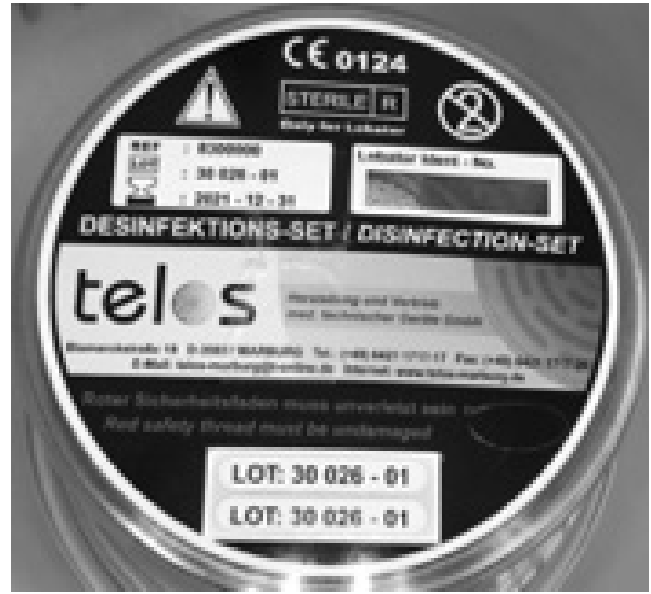

Рис. 2. Контейнер с заготовленной головкой бедренной кости

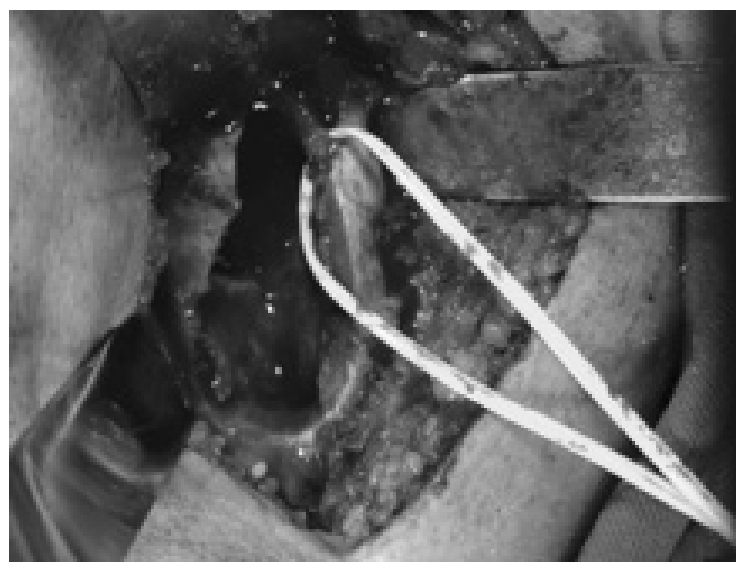

Рис. 4. Мобилизация сосудисто-нервного пучка нижней челюсти

По сравнению с искусственными материалами-заменителями кости, такими как костный цемент, керамика из гидроксиапатита, или же материалом из бычьей кости, важнейшее достоинство аллогенных трансплантатов кости заключается в их способности к остеокондуктивному и, частично, остеоиндуктивному действию $[1,6-8]$.

\section{Материалы и методы исслеАования}

После операции по удалению объемного новообразования нижней челюсти, подтвержденного ранее ПГИ, использовали для заполнения образовавшейся полости 


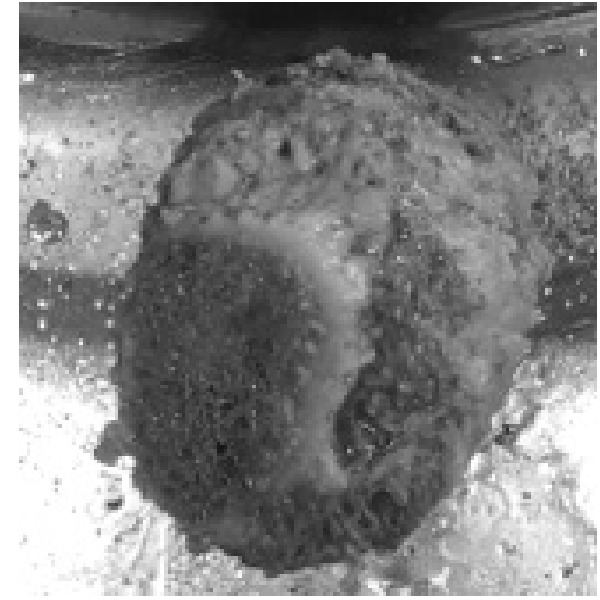

Рис. 5. Заготовленная ранее головка бедренной кости

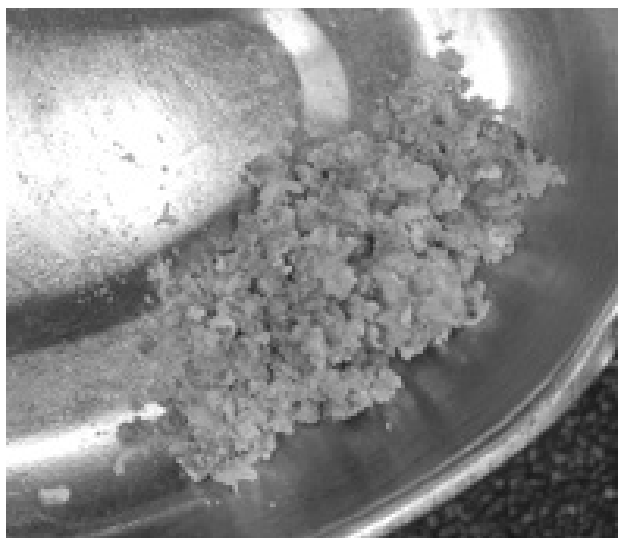

Рис. 7. Аллокостный конгломерат готовый к трансплантации

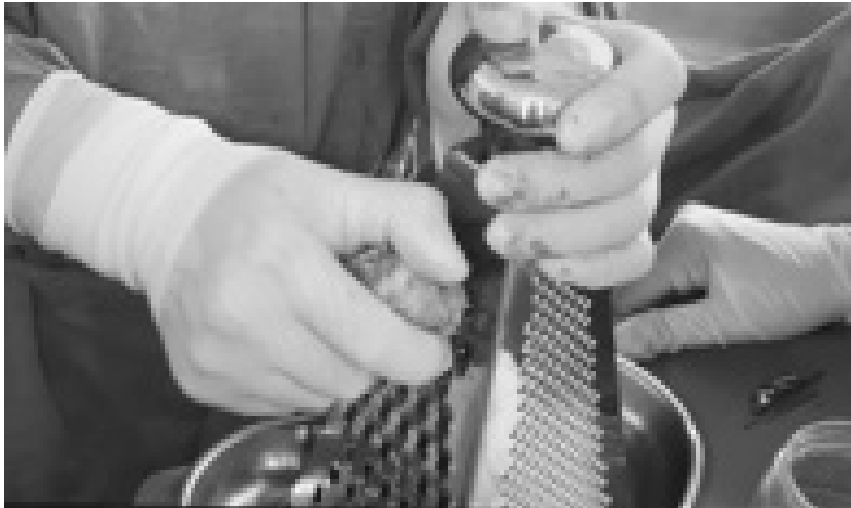

Рис. 6. Измельчение твердой костной структуры

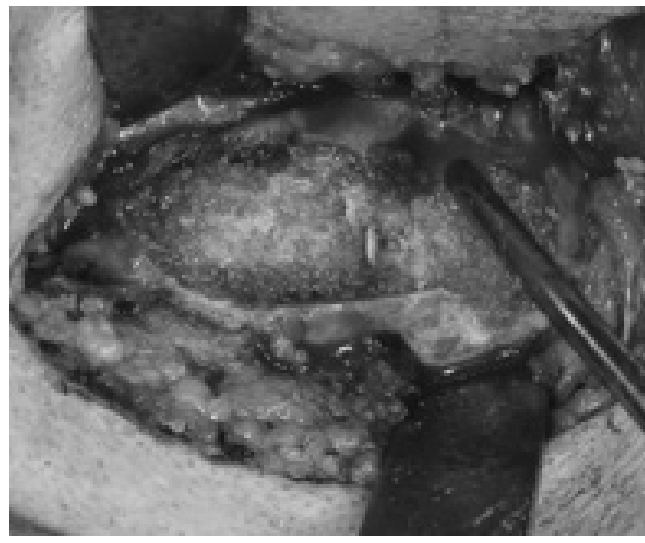

Рис. 8. Вид костной раны после трансплантации аллокостного материала головки бедренной кости

но обширное объёмное образование тела, угла нижней челюсти слева с поражением мыщелкового и венечного отростка. (Рис. 1).

До выполнения ПГИ консультирован специалистами, рекомендована резекция пораженного участка нижней челюсти с реконструкцией аутокостным трансплантатом малоберцовый кости. После получения данных ПГИ - кератокиста, принято решение о выполнении открытого удаления новообразования нижней челюсти с одномоментной реконструкцией образовавшегося дефекта костной стружкой полученной из губчатой кости, которую отбирали в процессе операции по замене тазобедренного сустава из проксимального тела бедренной кости и предоставленную банком костной ткани ККБ№ 1 (Рис. 2). 


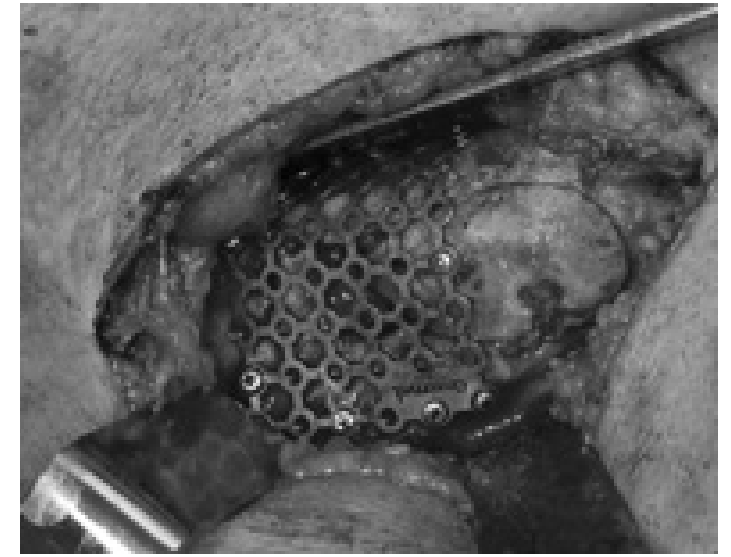

Рис. 9. Часть истонченной наружной кортикальной пластинки нижней челюсти уложена в область дефекта

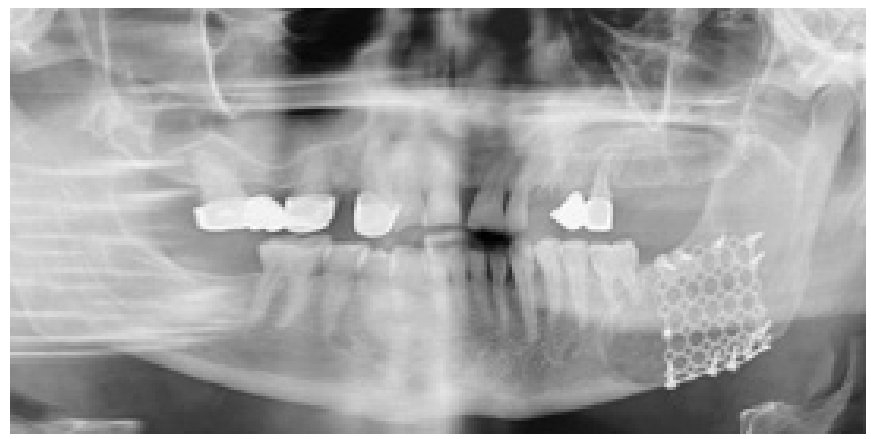

Рис. 11. Рентгенограмма через 3 месяца после реконструктивного вмешательства

\section{Результаты}

и обсу» $\Delta$ ение

Наружным доступом выполнено удаление новообразования. (Рис. 3).

После выделен и мобилизован сосудисто-нервный пучок (Рис. 4).

После ревизии всех карманов костной раны приступали к приготовлению костной алло стружки. (Рис. 5, 6, 7).

Для придания жесткости нижней челюсти в области зоны реконструкции уложена и фиксирована титановыми мини винтами титановая сетка.

Через 3 месяца клинических проявлений со стороны зоны оперативного вмешательства не наблюдалось.

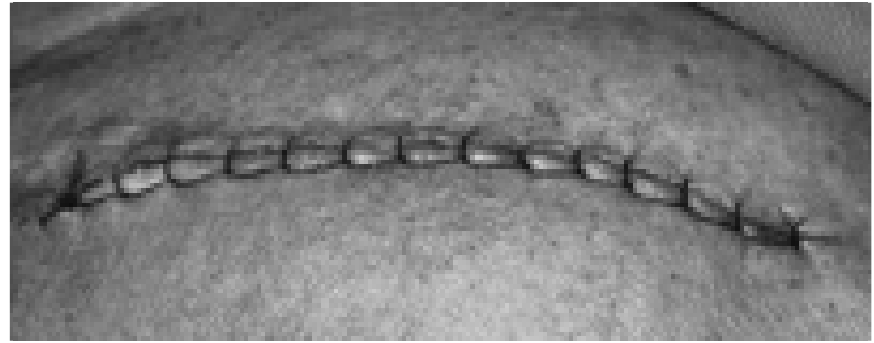

Рис. 10. Вид ушитой раны. Дренирование раны не выполняли

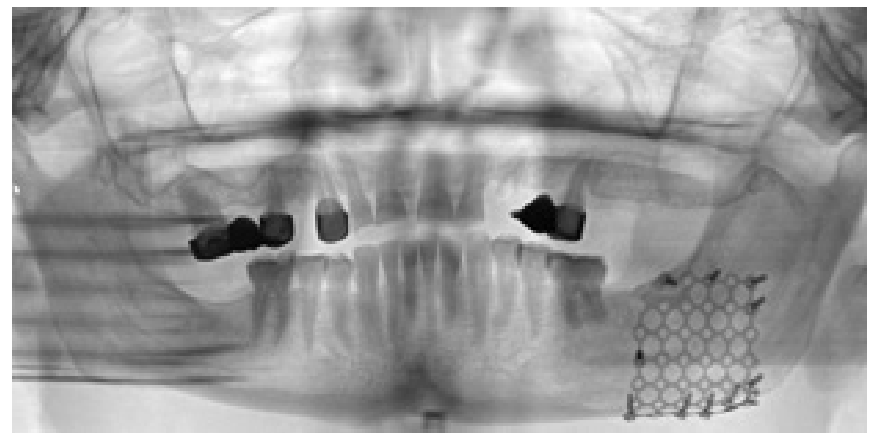

Рис. 12. Рентгенограмма через 6 месяцев после реконструктивного вмешательства

Рентгенологически определялись признаки формирования губчатой костной ткани, края костного дефекта выражены умеренно с положительной тенденцией к формированию костного рисунка. В период наблюдения 6 месяцев, по сравнению с осмотром 3 месяца, было определено достоверное различие в костном рисунке на выполненных рентгенологических исследованиях, границы костной раны не определяются, костная архитектоника в области реконструкции восстановлена в полном объеме.

Представленные результаты подтверждают возможность положительного применения для реконструкции образовавшегося дефекта нижней челюсти, костную стружку, полученную из губчатой кости, которую отбирали в процессе операции по замене тазобедренного сустава из проксимального тела бедренной кости обработанные и хранившиеся в условиях костного банка ККБ № 1. 


\section{ЛИТЕРАТУРА}

1. Бернадский, Ю.И. Травматология и восстановительная хирургия челюстно-лицевой области.—M., 2003. — 456 c.

2. Клиническая оперативная челюстно-лицевая хирургия / В. Н. Балин [и др.].—СПб., 1998.—592 с.

3. Пластическая и реконструктивная хирургия лица / Под ред. А. Д. Пейпла; Пер. с англ.—М., 2007.— 951 с.

4. Соколов В.Н., Аветиков Д. С. Пластическая реконструктивно-восстановительная и косметическая хирургия: Рук-во для интернов и врачей. — М., 2004.— $342 \mathrm{c}$.

5. Тимофеев, А. А. Основы челюстно-лицевой хирургии: Учебное пособие / А. А. Тимофеев.—M., 2007.—696 с.

6. Handschel, J. Nonvascularized iliac bone grafts for mandibular reconstruction — requirements and limitations / J. Handschel, H. Hassanyar; R. A. Depprich // In Vivo. - 2011. - Vol. 25 (5). - P. 795-799.

7. Тесевич Л.И., Горбачев Ф. А. Клинический опыт и хирургические аспекты пластического устранения костных дефектов с нарушением непрерывности нижней челюсти с использованием неваскуляризированных аутотранстплантатов из гребня подвздошной кости // Международные обзоры: клиническая практика и здоровье. 2016. № 1. С. 84-102.

8. Иорданишвили А.К., Музыкин М. И., Шенгелия Е. В., Поплавский Д. В. Опыт применения современного отечественного остеорепаративного материала в хирургической стоматологии // Курский научно-практический вестник «Человек и его здоровье». 2016. № 1. С. $26-31$.

(с) Дедиков Дмитрий Николаевич (avers_23@mail.ru).

Журнал «Современная наука: актуальные проблемы теории и практики»

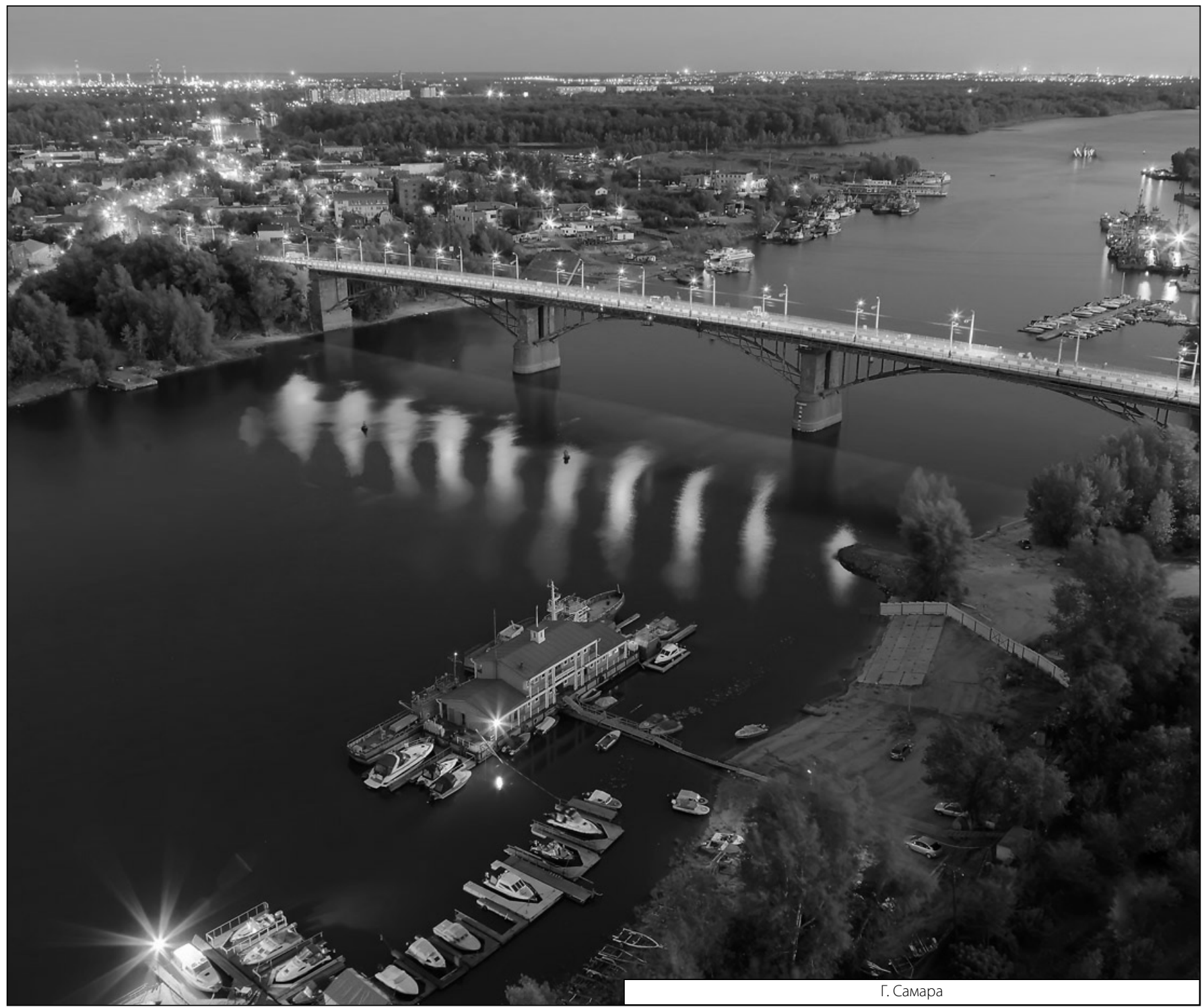

